Columbia International Publishing

American Journal of Agricultural Science and Technology

(2015) Vol. 3 No. 1 pp. 24-37

doi:10.7726/ajast.2015.1003

Research Article

\title{
On the Presence of Steryl Glucosides in Virgin Olive Oil and their Relationship with other Minor Compounds: Untangling the Skein
}

\author{
Raquel B. Gómez-Coca1*, Rosario Cruz-Hidalgo ${ }^{1}$, Gabriel D. Fernandes², Daniel Barrera-Arellano², \\ María del Carmen Pérez-Camino ${ }^{1}$, and Wenceslao Moreda ${ }^{1}$
}

Received 17 July 2015; Published online 17 October 2015

(C) The author(s) 2015. Published with open access at www.uscip.us

\begin{abstract}
This work extends previous research regarding the role of (esterified) steryl glucosides -(E)SG- in olive oil. In line with previous research and to contribute to a comprehensive olive oil chemical characterization, we have determined the profile and content of these compounds in different mono-variety virgin olive oils using cholesterol $\beta$-D-glucoside (ChSG) as single internal standard. To do this, we have collected 22 types of olive cultivars, extracted the oils by the Abencor ${ }^{\circledR}$ method and applied a formerly developed SPE protocol. We have also determined the corresponding response factors with respect to the internal standard. Additionally, we have analyzed some of the purity and quality parameters included in the Regulations with the aim of understanding their relationship with those sterol derivatives. Results show the feasibility of using ChSG as internal standard, shortening the global time of analysis. They also confirm the suitability of the limits previously established for the presence of ESG in olive oil $\left(0.2-14.0 \mathrm{mg}^{-1} \mathrm{~kg}^{-1}\right)$, but almost double those for SG (up to $4.77 \mathrm{mg} \cdot \mathrm{kg}^{-1}$ ). Data also indicates the lack of a direct, stoichiometric relationship between some possible substrates (sterols, free fatty acids and related compounds) and the products -(E)SG-. Future lines of research are therefore outlined.
\end{abstract}

Keywords: Esterified Steryl Glucosides (ESG); Minor Compounds; Olive Oil; Purity Parameters; Quality Parameters; Steryl Glucosides (SG)

\section{Abbreviations}

ChSG, cholesterol $\beta$-D-glucoside; (E)AvSG, (esterified) $\Delta 5$ - avenasteryl glucoside; (E)BSSG, (esterified) $\beta$-sitosteryl glucoside; (E)CSG, (esterified) campesteryl glucoside; ES, esterified sterols;

*Corresponding e-mail: raquel.coca@ig.csic.es

1 Instituto de la Grasa -CSIC-, Universidad Pablo de Olavide - Building 46, Ctra. de Utrera, km. 1, E-41013, Sevilla, Spain

2 Fats and Oils Laboratory, Faculty of Food Engineering, University of Campinas, 13083-970 Campinas, SP, Brazil 
Raquel B. Gómez-Coca, Rosario Cruz-Hidalgo, Gabriel D. Fernandes, Daniel Barrera-Arellano, María del Carmen Pérez-Camino, and Wenceslao Moreda / American Journal of Agricultural Science and Technology

(2015) Vol. 3 No. 1 pp. 24-37

ESG, esterified steryl glucosides; (E)SG, (esterified) steryl glucosides -meaning either of the two or both species-; (E)SSG, esterified stigmasteryl glucoside; EtOH, ethanol; EC, European commission; FAAE, fatty acid alkyl esters; FAME, fatty acid methyl esters; FAEE, fatty acid ethyl esters; FFA, free fatty acid; FID, flame ionization detector; FS, free sterols; GC, gas chromatography; IOC, International Olive Council; IS, Internal Standard; LOD, limit of detection; MeOH, methanol; PCA, Principal Component Analysis; SG, steryl glucosides; SPE, solid phase extraction; TLC, thin layer chromatography.

\section{Introduction}

According to the IOC (2013a), virgin olive oil is obtained from the fruit of the olive tree by mechanical or other physical procedures under conditions, thermal conditions particularly, that do not lead to alterations in the oil. No treatment other than washing, decantation, centrifugation and filtration is allowed. The product, which is actually olive juice, is not only attractive because of its flavor-enhancing properties when properly used during cooking, but also because of its health benefits (Buckland \& González, 2010). Among a large number of minor compounds present in virgin olive oil, phytosterols (FS and ES) belong to a group traditionally responsible for lowering blood cholesterol level (Pollak, 1953; Mackay \& Jones, 2011). However, it has been demonstrated that also (E)SG hinder cholesterol absorption in the gastrointestinal tract (Lin et al., 2009; Lin et al., 2011), making virgin olive oil intake even more appealing. Virgin olive oil is of great economic importance for the countries of the Mediterranean basin, with Spain being the largest producer in the world (Vossen, 2013). However new producers such as Georgia, Saudi Arabia, India and Botswana are entering the olive oil market, making the establishment of up-to-date mechanisms for quality control and fraud detection important issues.

Traditionally, control strategies have failed to keep pace with fraudulent practices. One of the most common schemes consists of mixing virgin olive oil with olive oil of lower quality or even with seed oils (including that from olive-stones) at concentrations that make the detection of the extraneous fat unlikely. Various chromatographic techniques have been studied to detect this and other adulterations (Christopoulou et al., 2004; Damirchi et al., 2005) but results have not always been conclusive and thus the search for new methods of detection continues. With this in mind it is easy to understand the usefulness of a comprehensive olive oil chemical characterization, including an ever wider set of minor compounds, in this case steryl glucosides either free (Gómez-Coca et al., 2012) or esterified (Gómez Coca et al., 2013; Gómez-Coca et al., 2014a). SG are phytosterol conjugates in which one glucose moiety binds at the C3 position of the FS residue via an acetyl bond. This molecule can be esterified to a fatty acid at the C6' position, giving rise to ESG (Gómez-Coca et al., 2013). The role of both kinds of phytosterol derivatives is still unclear (Grille et al., 2010), although a number of relevant studies are being carried out both in biodiesel (Bondioli, 2009; Lacoste et al., 2009) and in edible matrices other than olive oil (Nyström et al, 2012; Münger \& Nyström, 2014).

This work is a continuation of a series of approaches towards understanding the role of (E)SG in virgin olive oil, not only from a quantitative/qualitative point of view, but also in terms of their relationship with other oil components. In order to establish the bases for the use of these oil components as fraud indicators, we have started investigating their possible relationship with 
Raquel B. Gómez-Coca, Rosario Cruz-Hidalgo, Gabriel D. Fernandes, Daniel Barrera-Arellano, María del Carmen Pérez-Camino, and Wenceslao Moreda / American Journal of Agricultural Science and Technology

(2015) Vol. 3 No. 1 pp. 24-37

other parameters, some of which are included in Regulation (EC, 1991; IOC, 2011; IOC, 2013a) as in the cases of FS, waxes, aliphatic alcohols, and FAAE. While previous research focused on growth conditions demonstrating the pedoclimate dependence of these compounds (Gómez-Coca et al., 2014a), the objective here is to study the occurrence of (E)SG in a wide variety of virgin olive oils as a function of cultivar.

\section{Material and Methods}

\subsection{Standard Solutions}

All analytical standards were purchased from Sigma Aldrich Co. LLC (St. Louis, Missouri, USA). Stock solutions of sterols and aliphatic alcohols were prepared by dissolving the standards, alphacholestanol and n-eicosanol, respectively, in chloroform with a concentration of $1 \mathrm{mg} \cdot \mathrm{mL}^{-1}$. Stock solutions of ChSG $\left(100 \mu \mathrm{g} \cdot \mathrm{mL}^{-1}\right)$ were made by dissolving it in a chloroform: methanol $(2: 1$, by volume) blend. Stock solutions of lauryl arachidate (IS for waxes) and methyl heptadecanoate (IS for FAAE) were prepared by dissolving the commercial products in heptane at concentrations of $0.02 \mathrm{mg} \cdot \mathrm{mL}^{-1}$ and $0.005 \mathrm{mg} \cdot \mathrm{mL}^{-1}$, respectively.

\subsection{Chemicals Used}

Carlo Erba (Sabadell, Spain) supplied trichloromethane; Fluka (Buchs, Switzerland) hexamethyldisilazane and chloromethylsilane; J.T. Baker (Tarragona, Spain) acetic acid. Merck (Darmstand, Germany) provided heptane, tert-butylmethyl ether, silica gel and sodium thiosulfate; Panreac (Chicago, Illinois, USA) hexane, potassium hydroxide and sodium sulfate; Scharlau (Barcelona, Spain) potassium iodide; Sigma Aldrich (Munich, Germany) pyridine and VWR International LLC (Radnor, Pennsylvania, USA) acetone, ethanol, ethyl ether and methanol. All chemical reagents were analytical grade.

\subsection{Samples}

This study was carried out with single-variety virgin oils extracted from 22 olive fruit cultivars, hand-picked in the 2013/2014 crop year from an irrigated orchard in Hacienda Guzman (La Rinconada, Seville, Spain), where they had been grown under optimal conditions. These cultivars were: Adramitini (Greece), Ascolana (Italy), Blanqueta (Spain), Bouteillan (France), Chemlal de Kabilye (Algeria), Cipresino (Italy), Coratina (Italy), Empeltre (Spain), Frantoio (Italy), Hojiblanco (Spain), Imperial (Spain), Kalamon (Greece), Koroneiki (Greece), Leccino (Italy), Lechin (Spain), Manzanilla (Spain), Negral (Spain), Nevado Azul(Spain), Pendolino (Italy), Picual (Spain), Rapasayo (Spain) and Sigoise (Algeria). In all cases we used deep green to black skin olives whose maturity indexes were determined to be from 0 to 4 according to IOC, (2011). Oils were extracted using an Abencor ${ }^{\circledR}$ system following a procedure described by Gómez-Coca et al. (2014a).

\subsection{Analysis of Steryl Glucosides}

The SPE process utilized had been developed previously (Gómez-Coca et al., 2013). The method consists of the conditioning of the cartridges (ExtraBond Si 1 g; Scharlab S.L., Barcelona, Spain) with 
Raquel B. Gómez-Coca, Rosario Cruz-Hidalgo, Gabriel D. Fernandes, Daniel Barrera-Arellano, María del Carmen Pérez-Camino, and Wenceslao Moreda / American Journal of Agricultural Science and Technology

(2015) Vol. 3 No. 1 pp. 24-37

$5 \mathrm{~mL}$ tert-butyl methyl ether, $5 \mathrm{~mL}$ hexane, $5 \mathrm{~mL}$ chloroform, and $10 \mathrm{~mL}$ of a newly prepared blend consisting of chloroform:methanol $4: 1$, by volume, applied one after the other. Samples are then quantitatively transferred using $1 \mathrm{~mL}$ chloroform to wash the walls of the containers. The loaded cartridges are washed with $10 \mathrm{~mL}$ hexane, $10 \mathrm{~mL}$ of tert-butyl methyl ether, and $10 \mathrm{~mL}$ chloroform, applied consecutively. The steryl glucosides are eluted with $5 \mathrm{~mL}$ of the chloroform:methanol 4:1 (v/v) solution. The procedure was carried out under negative pressure $(1 \mathrm{mmHg})$ in a vacuum manifold. The eluted fractions are evaporated to dryness under nitrogen flux, derivatized and chromatographed using cool on-column injection. Solutions consisting of pyridine:hexamethyldisilazane:chlorotrimethylsilane (9:3:1, by volume) were used to derivatize hydroxyl groups when needed. In order to carry out the quantitative evaluation of both SG and ESG using ChSG as an internal standard, response coefficients for each species were (re)-calculated and averaged. The FID sensitivity towards ChSG was proven to be 0.9 and 1.6 times lower than towards SG and ESG, respectively. Therefore the respective areas must be corrected using the data integration software. The calculation of the concentration of each individual compound, in $\mathrm{mg} \mathrm{kg}^{-1}$, were performed as follows:

(E)SG $x=A x \times m I S / A I S \times m S$

Where:

$A x$ is the peak area for the (E)SG $x$ divided by the its correction factor, $A I S$ is the area of the ChSG peak, $m I S$ is the mass of ChSG added, in milligrams, $m S$ is the mass of the sample used for the determination, in grams.

\subsection{Quality Parameters: Fatty Acid Alkyl Esters (FAAE) and Acidity Value}

The determination of the content of methyl and ethyl esters of fatty acids was carried out following the most recent procedure recommended by the International Olive Council (2012) in which $3 \mathrm{~g}$ silica gel suspended in n-hexane is utilized for separation through column chromatography. All analytes elute within the same fraction and are taken to GC. The determination of the free acidity was carried out according to the procedure published by the European Commission (1991). Samples were dissolved in a mixture of equal parts by volume of diethyl ether and $95 \%$ ethanol, and titrated using a titrated $0.1 \mathrm{M}$ potassium hydroxide ethanolic solution, utilizing phenolphthalein as indicator. The acidity was expressed as a percentage by weight of oleic acid and the result as the arithmetic mean of two calculations.

\subsection{Determination of Purity Parameters: Waxes, Aliphatic Alcohols, and Sterols}

Wax isolation and analysis was carried out along with that of FAAE following the procedure given by the International Olive Council (2012) as previously described. According to this, individual waxes and alkyl esters are separated as a function of the number of carbon atoms. The extraction of aliphatic and steroidal alcohols was made simultaneously following the procedures published by the International Olive Council (2003; 2013b). The oil, together with the respective IS n-eicosanol and $\alpha$-cholestanol, was saponified with ethanolic potassium hydroxide and the unsaponifiable 
Raquel B. Gómez-Coca, Rosario Cruz-Hidalgo, Gabriel D. Fernandes, Daniel Barrera-Arellano, María del Carmen Pérez-Camino, and Wenceslao Moreda / American Journal of Agricultural Science and Technology

(2015) Vol. 3 No. 1 pp. 24-37

extracted with diethyl ether. The sterols and aliphatic alcohols fractions were then isolated through TLC on a basic silica gel plate, scraped off, silylated and analyzed by GC.

\subsection{Instrumentation}

GC analyses of the steryl glucosides were carried out according to the published procedure (GómezCoca et al., 2013). The same chromatograph (Agilent 6890N equipped with an Agilent 7683B Automatic Liquid Sampler and FID) was utilized for analyzing aliphatic and steroideal alcohols, under the following conditions: $1.0 \mu \mathrm{L}$ injection volume, hydrogen carrier gas at $1 \mathrm{~mL} \cdot \mathrm{min}^{-1}$ and split injection (10:1). The oven temperature program was: $250{ }^{\circ} \mathrm{C}$ (35 min), and both injector and detector were at $300^{\circ} \mathrm{C}$. GC analyses of the FAAE were carried out with an Agilent $6890 \mathrm{~N}$ Gas Chromatograph under the following conditions: TRB-5HT column (5\% diphenyl-95\% dimethylpolysiloxane; 15 m x $0.32 \mathrm{~mm}$ ID x $0.10 \mu \mathrm{m}$ film; Teknokroma, Sant Cugat del Vallés, Barcelona, Spain) $1.0 \mu \mathrm{L}$ injection volume, hydrogen carrier gas at $9.6 \mathrm{~mL} \mathrm{~min}^{-1}$ and on-column injection. The oven temperature program was: $70{ }^{\circ} \mathrm{C}\left(0 \mathrm{~min}\right.$ initial temp), then rising at $15{ }^{\circ} \mathrm{C} \mathrm{min}^{-}$ 1 to $220{ }^{\circ} \mathrm{C}(0 \mathrm{~min}), 10{ }^{\circ} \mathrm{C} \mathrm{min}^{-1}$ to $310^{\circ} \mathrm{C}(0 \mathrm{~min})$ and $5{ }^{\circ} \mathrm{C} \mathrm{min}^{-1}$ to $340{ }^{\circ} \mathrm{C}$, then hold for $8 \mathrm{~min}$. The injector and detector temperatures were $80{ }^{\circ} \mathrm{C}$ and $350{ }^{\circ} \mathrm{C}$ respectively.

\subsection{Statistical Analysis}

All statistical analyses were run using SPSS Statistics software. First an analysis of correlation between variables, including quality and purity parameters, by the Spearman correlation coefficient (statistical significance of $\mathrm{p}<0.05$ ) was carried out and then samples were grouped by principal component analysis (PCA). The graphics was plotted using Microsoft Excel 2010 software.

\section{Results and Discussion}

\subsection{Analysis of Steryl Glucosides}

Steryl glucosides are sterol derivatives whose presence in olive oil has not yet been studied in depth, neither the possible relationship between these compounds and other oil components. So far eight different steryl glucosides have been identified in olive oil consisting of molecules of campesterol, stigmaterol, $\beta$-sitosterol and $\Delta 5$-avenasterol in which a glucose moiety is bound at the C3 position via an acetyl bond forming either free steryl glucosides (SG: CSG, SSG, BSSG and AvSG, respectively) or their esterified counterparts (ESG: ECSG, ESSG, EBSSG and EAvSG, respectively) if they hold a fatty acid (presumably oleic, palmitic or linoleic acids, but also stearic or palmitoleic residues) at C6'. Among these species $\beta$-sitosterol derivatives (BSSG and EBSSG) were the most common ones (Gómez-Coca et al., 2014a). During SG and ESG analysis, both kinds of compounds appear in the same chromatogram (Figure 1). 
Raquel B. Gómez-Coca, Rosario Cruz-Hidalgo, Gabriel D. Fernandes, Daniel Barrera-Arellano, María del Carmen Pérez-Camino, and Wenceslao Moreda / American Journal of Agricultural Science and Technology (2015) Vol. 3 No. 1 pp. 24-37

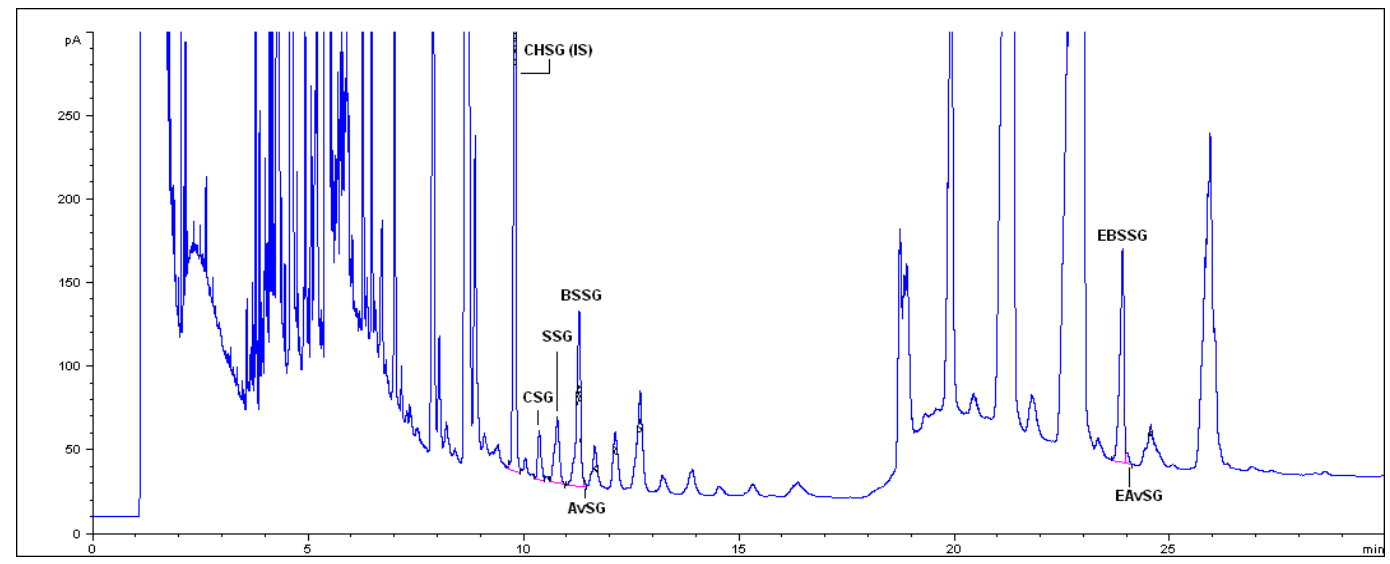

Fig. 1. GC-FID chromatogram for steryl glucosides and esterified steryl glucosides in virgin olive oil together with the internal standard cholesteryl glucoside (ChSG). CSG, campesteryl glucoside; SSG, stigmasteryl glucoside; BSSG, $\beta$-sitosteryl glucoside; AvSG, $\Delta 5$-avenasteryl glucoside; EBSSG, esterified $\beta$-sitosteryl glucoside; EAvSG, esterified $\Delta 5$-avenasteryl glucoside.

Table 1 Total Steryl Glucosides Contents $\left(\mathrm{mg}^{\mathrm{kg}}{ }^{-1}\right)$ of Olive Oil from Different Cultivars, and Relative Composition Regarding Campesteryl Glucoside (CSG), Stigmasteryl Glucoside (SSG), $\beta$-Sitosteryl Glucoside (BSSG), and $\Delta 5$-Avenasteryl Glucoside (AvSG). ${ }^{\text {a }}$

\begin{tabular}{|l|ll|ll|ll|ll|ll|}
\hline & \multicolumn{2}{|c|}{ CSG } & \multicolumn{2}{c|}{ SSG } & \multicolumn{2}{c|}{ BSSG } & \multicolumn{2}{c|}{ AvSG } & \multicolumn{2}{c|}{ Total } \\
Samples & \% & SD & \% & SD & \% & SD & \% & SD & mg.kg-1 & SD \\
\hline Adramitini & 11.11 & 1.23 & 32.73 & 2.73 & 54.42 & 1.22 & 1.74 & 0.28 & 3.74 & 0.06 \\
Ascolana & 22.01 & 0.20 & NQ & & 75.70 & 0.04 & 2.29 & 0.16 & 3.42 & 0.34 \\
Blanqueta & 14.45 & 2.25 & 25.06 & 4.65 & 56.54 & 2.19 & 3.94 & 0.80 & 3.19 & 0.60 \\
Bouteillan & 10.03 & 2.38 & 29.94 & 3.29 & 58.95 & 1.18 & 1.08 & 0.07 & 2.73 & 0.07 \\
Chemlal K. & 28.67 & 1.29 & 5.71 & 1.88 & 62.36 & 0.87 & 3.26 & 0.29 & 1.82 & 0.03 \\
Cipresino & 6.39 & 0.40 & NQ & & 90.82 & 0.49 & 2.79 & 0.23 & 2.24 & 0.05 \\
Coratina & 8.68 & 2.68 & $\mathrm{NQ}$ & & 88.28 & 3.26 & 3.04 & 0.58 & 2.25 & 0.02 \\
Empeltre & 8.60 & 0.49 & 10.24 & 0.34 & 81.16 & 0.16 & $\mathrm{NQ}$ & & 2.88 & 0.04 \\
Frantoio & 16.71 & 3.31 & 25,93 & 1.94 & 72.86 & 10.07 & 2.47 & 0.43 & 3.29 & 0.03 \\
Hojiblanco & 16.76 & 1.50 & 6.52 & 0.12 & 75.75 & 1.39 & 0.97 & 0.01 & 2.45 & 0.07 \\
Imperial & 17.24 & 0.31 & 27.97 & 0.10 & 53.95 & 0.01 & 0.84 & 0.21 & 3.67 & 0.12 \\
Kalamon & 11.76 & 1.55 & $\mathrm{NQ}$ & & 86.14 & 0.08 & 2.10 & 1.46 & 2.42 & 0.07 \\
Koroneiki & 9.62 & 0.63 & $\mathrm{NQ}$ & & 87.62 & 0.32 & 2.76 & 0.91 & 0.78 & 0.03 \\
Leccino & 20.95 & 4.37 & 8.59 & 1.93 & 67.83 & 1.94 & 2.63 & 0.50 & 2.10 & 0.09 \\
Lechín & 14.89 & 0.53 & 19.07 & 2.61 & 61.47 & 2.62 & 4.57 & 0.40 & 4.77 & 0.21 \\
Manzanilla & 13.69 & 0.19 & 25.66 & 0.11 & 59.17 & 0.55 & 1.48 & 0.25 & 4.59 & 0.06 \\
Negral & 24.75 & 3.25 & 19.07 & 2.83 & 54.59 & 4.31 & 1.59 & 1.11 & 4.34 & 0.05 \\
Nevado A. & 27.78 & 0.01 & 27.88 & 0.97 & 42.67 & 0.74 & 1.67 & 0.22 & 4.24 & 0.50 \\
Pendolino & 13.00 & 3.32 & $\mathrm{NQ}$ & & 85.66 & 8.02 & 4.72 & 0.63 & 1.65 & 0.03 \\
Picual & 16.48 & 0.83 & $\mathrm{NQ}$ & & 83.46 & 0.88 & $\mathrm{NQ}$ & & 1.90 & 0.07 \\
Rapasayo & 21.37 & 1.67 & 4.95 & 0.66 & 72.43 & 1.00 & 1.26 & 0.01 & 1.94 & 0.03 \\
Sigoise & 25.88 & 1.29 & 9.26 & 1.94 & 63.75 & 1.89 & 1.11 & 0.86 & 3.15 & 0.34 \\
\hline
\end{tabular}

a A minimum of two independent measures was made on each case. The standard deviation is also given; NQ (Non Quantified) 
Raquel B. Gómez-Coca, Rosario Cruz-Hidalgo, Gabriel D. Fernandes, Daniel Barrera-Arellano, María del Carmen Pérez-Camino, and Wenceslao Moreda / American Journal of Agricultural Science and Technology

(2015) Vol. 3 No. 1 pp. 24-37

In the cases of the oils under study, the four SG were identified in $64 \%$ of the samples (Table 1). SSG could not be clearly recognized in seven out of 22 cases, whereas AvSG was not measurable in two instances. The behavior is somehow different as far as ESG are concern (Table 2), since the coelution of other compounds within the ESG Rt window made the identification of the different species less straightforward. In this manner, in $86 \%$ of the samples EAvSG could be unmistakably recognized, whereas ECSG and ESSG were only present above the method's LOD in $14 \%$ and 36\% of the oils, respectively. However, earlier results showed that ECSG was completely absent and ESSG was detected in only $5 \%$ of the instances (Gómez-Coca et al., 2014a).

Table 2 Total Esterified Steryl Glucosides (ESG) Contents (mg.kg-1) of Olive Oil from Different Cultivars, and Relative Composition Regarding Esterified Campesteryl Glucoside (ECSG), Esterified Stigmasteryl Glucoside (ESSG), Esterified $\beta$-Sitosteryl Glucoside (EBSSG), and Esterified $\Delta 5$-Avenasteryl Glucoside (EAvSG). ${ }^{\mathrm{a}, \mathrm{b}}$

\begin{tabular}{|l|ll|ll|ll|ll|ll|l|}
\hline & \multicolumn{2}{|c|}{ ECSG } & \multicolumn{2}{c|}{ ESSG } & \multicolumn{2}{c|}{ EBSSG } & \multicolumn{2}{c|}{ EAvSG } & \multicolumn{2}{c|}{ Total } & R \\
Samples & \% & SD & \% & SD & \% & SD & \% & SD & mg.kg-1 & SD & \\
\hline Adramitini & 3.26 & 0.59 & NQ & & 94.23 & 0.90 & 2.51 & 0.31 & 1.47 & 0.01 & 2.55 \\
Ascolana & NQ & & NQ & & 96.64 & 0.09 & 3.36 & 0.09 & 1.91 & 0.20 & 1.79 \\
Blanqueta & 3.26 & 0.20 & NQ & & 88.88 & 0.01 & 3.94 & 0.20 & 1.01 & 0.07 & 3.16 \\
Bouteillan & NQ & & NQ & & 98.01 & 0.51 & 1.99 & 0.51 & 0.94 & 0.01 & 2.90 \\
Chemlal K. & NQ & & NQ & & 95.33 & 0.41 & 4.67 & 0.41 & 1.10 & 0.02 & 1.65 \\
Cipresino & NQ & & 28.95 & 10.79 & 69.22 & 10.39 & 1.82 & 0.40 & 0.79 & 0.03 & 2.82 \\
Coratina & NQ & & 33.28 & 4.75 & 65.02 & 5.30 & 1.71 & 0.55 & 0.78 & 0.05 & 2.88 \\
Empeltre & NQ & & NQ & & 99.29 & 0.09 & 0.71 & 0.09 & 1.04 & 0.05 & 2.76 \\
Frantoio & 3.88 & 0.79 & NQ & & 93.01 & 0.28 & 3.11 & 0.51 & 2.30 & 0.13 & 1.43 \\
Hojiblanco & NQ & & 25.05 & 4.23 & 74.11 & 4.40 & 0.85 & 0.17 & 0.55 & 0.03 & 4.48 \\
Imperial & NQ & & 17.56 & 0.94 & 80.61 & 1.22 & 1.83 & 0.28 & 1.04 & 0.09 & 3.54 \\
Kalamon & NQ & & NQ & & 100.00 & 0.01 & NQ & & 0.60 & 0.18 & 4.02 \\
Koroneiki & NQ & & 25.46 & 5.53 & 72.52 & 5.12 & 2.02 & 0.42 & 1.12 & 0.01 & 0.70 \\
Leccino & NQ & & NQ & & 95.71 & 0.67 & 4.29 & 0.67 & 0.72 & 0.20 & 2.92 \\
Lechín & NQ & & NQ & & 92.90 & 0.47 & 7.10 & 0.47 & 2.11 & 0.09 & 2.26 \\
Manzanilla & NQ & & 8.44 & 2.76 & 88.08 & 2.37 & 3.48 & 0.39 & 1.92 & 0.02 & 2.40 \\
Negral & NQ & & NQ & & 96.53 & 1.04 & 3.47 & 1.04 & 1.97 & 0.41 & 2.20 \\
Nevado A. & NQ & & NQ & & 96.04 & 0.48 & 3.96 & 0.48 & 3.01 & 0.28 & 1.41 \\
Pendolino & NQ & & NQ & & 93.96 & 0.48 & 6.04 & 0.48 & 1.39 & 0.01 & 1.19 \\
Picual & NQ & & 37.21 & 0.08 & 62.79 & 0.08 & NQ & & 0.84 & 0.10 & 2.27 \\
Rapasayo & NQ & & 15.02 & 3.55 & 84.98 & 3.55 & NQ & & 0.53 & 0.01 & 3.66 \\
Sigoise & NQ & & NQ & & 95.33 & 1.13 & 4.67 & 1.13 & NQ & 0.04 & \\
\hline
\end{tabular}

a A minimum of two independent measures was made on each case.

The standard deviation is also given; NQ (Non Quantified).

b Last column shows the ratio (R= SG:ESG) between total free (SG) and esterified (ESG) steryl glucosides.

As far as quantitative results are concerned (Table 1), total SG concentrations were within the 0.78 \pm 0.03 to $4.77 \pm 0.21 \mathrm{mg} \cdot \mathrm{kg}^{-1}$ range. These amounts correspond to Koroneiki and Lechín samples, respectively. Comparisons between these results with those obtained formerly (Gómez-Coca et al., 2014a) show that the upper limit is 1.8 times higher than that previously established $\left(2.7 \mathrm{mg} \cdot \mathrm{kg}^{-1}\right)$. 
Raquel B. Gómez-Coca, Rosario Cruz-Hidalgo, Gabriel D. Fernandes, Daniel Barrera-Arellano, María del Carmen Pérez-Camino, and Wenceslao Moreda / American Journal of Agricultural Science and Technology

(2015) Vol. 3 No. 1 pp. 24-37

Regarding ESG, the maximum concentration found did not reach $3.5 \mathrm{mg} \cdot \mathrm{kg}^{-1}$, within the error limit, being the lowest threshold in $0.55 \pm 0.03 \mathrm{mg} \cdot \mathrm{kg}-1$. These concentrations are within the expected range (0.2 to $14.0 \mathrm{mg} \cdot \mathrm{kg}^{-1}$ ) (Gómez-Coca et al., 2014a).

The described behavior led us to accept the lack of dependence between the olive-fruit cultivar and the steryl glucoside content in virgin olive oil, and therefore to set the existence of limits for this kind of matrix as a whole. In addition, these comparisons support our previous conclusion regarding the influence of the pedoclimatic conditions (Gómez-Coca et al., 2014a) since both sets of samples have been obtained through the same system and differences can only be derived from agricultural practices. However, comparisons among the (E)SG composition observed for the different cultivars hint that some ESG (e.g. ESSG) might be species specific, suggesting the need for further studies. Associations between the two groups of glucosides make clear that SG are the most abundant species, since the SG:ESG ratio is greater than 1 in $95 \%$ of the samples. This agrees with some earlier results (Gómez-Coca et al., 2014a) but is opposite to others in which the usual trend was a SG:ESG ratio below 1 (Gómez-Coca et al., 2013). This last set of figures corresponded to samples obtained industrially, suggesting the importance of the extraction system in relationship with the amount of water utilized. Thus, it seems that the modern two- and three-phase decanters may be applying a volume of water high enough to sweep the more hydrophilic SG (whereas the bulky and more lipophilic ESG remain), in comparison with the Abencor $\AA$ procedure where very limited quantities of water have been utilized.

\subsection{Determination of Quality and Purity Parameters}

The election of the initial quality and purity parameters to be determined in looking for a possible correlation with steryl glucosides followed the logic that the presence of common substrates may condition the formation of one or another product. Thus, FS composition and content were chosen at once, with the aim of having enough data to confirm results from previous studies (Gómez-Coca et al., 2013). Additionally, free acidity was measured since the presence of FFA is necessary for SG esterification at C6'. Finally, other parameters such as FAAE, short-chain alcohols ( $\mathrm{MeOH}$ and EtOH) (Gómez-Coca et al., 2014b), waxes and aliphatic alcohols were considered, since they could be in a more or less indirect way responsible for the withdrawal of substrates (e.g. FFA) from the media. Table 3 shows the content of total FS (as the sum of desmethylsterols originating from originally free and esterified sterols) and the relative composition of those that could be identified as part of (E)SG.

Note that except for the cases of Koroneiki cv. and Rapasayo cv. The FS content in all samples were above the minimum limit set for virgin olive oil (EC, 2013a). It is true that those two varieties showed low (E)SG concentration, but not lower than other cultivars giving no apparent reason for their lack of compliance with Regulations. Interestingly, a number of varieties clearly form ESSG whereas ECSG could not be unequivocally detected, showing once again the independence of the synthetic routes for FS and (E)SG, since the usual trend in virgin olive oil is a campesterol content above the stigmasterol concentration. 
Raquel B. Gómez-Coca, Rosario Cruz-Hidalgo, Gabriel D. Fernandes, Daniel Barrera-Arellano, María del Carmen Pérez-Camino, and Wenceslao Moreda / American Journal of Agricultural Science and Technology

(2015) Vol. 3 No. 1 pp. 24-37

Table 4 displays free acidity, and wax and aliphatic alcohol contents, together with FAAE concentrations, calculated as the sum of FAME and FAEE. Data on short-chain aliphatic alcohol analysis have also been taken into account (Gómez-Coca et al., 2014b).

Regarding free acidity results (column 4) we observe that even if Adramitini and Manzanilla varieties reach the maximum allowed limit $(0.8 \%)$ for an oil to be considered as extra virgin (EC, 2013a), the ESG content is neither significantly higher nor lower than in the other cases. This point would require a deeper study of the formation kinetic of ESG since not only substrate availability (quantity and/or quality) but also storage conditions may influence the reaction shift. Regarding FAAE concentration (sum of FAME and FAEE), in no case are these oils out of the expected range for the extra virgin olive oil classification (EC, 2013a; EC, 2013b) although there are remarkable differences among varieties (e.g. Lechín vs. Picual cultivars). In line with this, the evaluation of the volatiles (short-chain alcohols as substrates for FAAE formation) was within expectations for virgin olive oils of moderately good quality, meaning concentrations below $14 \mathrm{mg} \mathrm{kg}^{-1}$ and $3 \mathrm{mg} \mathrm{kg}^{-1}$ for $\mathrm{MeOH}$ and EtOH, respectively (Gómez-Coca et al., 2014b). Finally, wax (formed by esterification between FFA and long-chain aliphatic alcohols) and aliphatic alcohol contents were also kept within the range given by Regulations (EC, 2013a) with no significant behavior.

Table 3 Total Desmethylsterol Contents $\left(\mathrm{mg}^{\mathrm{kg}}{ }^{-1}\right)$ of Olive Oil from Different Cultivars. The Relative Composition Regarding the Most Abundant Species in Olive Oil is Shown too. ${ }^{a} \mathrm{C}$, Campesterol;S, Stigmasterol; BS, $\beta$-Sitosterol, and Av, $\Delta 5$-Avenasterol.

\begin{tabular}{|l|ll|ll|ll|ll|ll|}
\hline & \multicolumn{2}{|c|}{ C } & \multicolumn{2}{|c|}{ S } & \multicolumn{2}{c|}{ BS } & \multicolumn{2}{c|}{ Av } & \multicolumn{2}{c|}{ Total } \\
Samples & \% & SD & \% & SD & \% & SD & \% & SD & mgkkg-1 & SD \\
\hline Adramitini & 3.9 & 0.01 & 1.1 & 0.01 & 87.5 & 0.01 & 3.5 & 0.08 & 1740 & 13 \\
Ascolana & 3.0 & 0.01 & 1.4 & 0.01 & 88.4 & 0.07 & 4.7 & 0.03 & 2377 & 42 \\
Blanqueta & 3.9 & 0.01 & 0.8 & 0.01 & 75.0 & 0.04 & 1.8 & 0.03 & 2358 & 16 \\
Bouteillan & 2.3 & 0.01 & 0.9 & 0.01 & 89.7 & 0.05 & 3.5 & 0.04 & 2274 & 46 \\
Chemlal K. & 3.3 & 0.01 & 0.9 & 0.01 & 84.5 & 0.08 & 5.9 & 0.13 & 1158 & 51 \\
Cipresino & 4.7 & 0.02 & 0.5 & 0.02 & 85.7 & 0.03 & 4.5 & 0.04 & 2349 & 7 \\
Coratina & 3.6 & 0.03 & 1.1 & 0.45 & 88.6 & 0.29 & 2.3 & 0.01 & 1197 & 56 \\
Empeltre & 3.6 & 0.02 & 0.7 & 0.05 & 92.5 & 0.34 & 0.6 & 0.02 & 1819 & 82 \\
Frantoio & 3.4 & 0.01 & 0.8 & 0.01 & 86.0 & 0.83 & 5.2 & 0.38 & 1818 & 51 \\
Hojiblanco & 2.7 & 0.04 & 0.8 & 0.02 & 91.2 & 0.05 & 1.4 & 0.10 & 1907 & 61 \\
Imperial & 3.4 & 0.01 & 0.9 & 0.01 & 88.9 & 0.23 & 3.3 & 0.10 & 2119 & 37 \\
Kalamon & 2.4 & 0.01 & 0.4 & 0.01 & 89.5 & 0.16 & 4.5 & 0.06 & 2781 & 17 \\
Koroneiki & 5.8 & 0.09 & 1.1 & 0.01 & 88.8 & 0.97 & 1.6 & 0.43 & 826 & 5 \\
Leccino & 3.0 & 0.05 & 1.3 & 0.01 & 83.9 & 0.14 & 6.6 & 0.03 & 1962 & 41 \\
Lechín & 3.7 & 0.01 & 1.1 & 0.02 & 78.7 & 0.08 & 12.1 & 0.04 & 2167 & 30 \\
Manzanilla & 2.8 & 0.02 & 1.4 & 0.02 & 88.9 & 0.12 & 3.0 & 0.09 & 1490 & 119 \\
Negral & 3.7 & 0.01 & 0.8 & 0.07 & 86.5 & 0.11 & 5.2 & 0.11 & 2444 & 51 \\
Nevado A. & 2.6 & 0.04 & 1.0 & 0.05 & 88.6 & 0.81 & 3.2 & 0.07 & 1926 & 5 \\
Pendolino & 2.7 & 0.01 & 0.8 & 0.04 & 86.9 & 0.09 & 4.4 & 0.08 & 1402 & 96 \\
Picual & 3.1 & 0.06 & 0.9 & 0.01 & 88.8 & 1.63 & 2.1 & 0.44 & 1306 & 48 \\
Rapasayo & 4.2 & 0.07 & 1.5 & 0.15 & 87.6 & 0.25 & 1.3 & 0.01 & 900 & 19 \\
Sigoise & 3.9 & 0.04 & 0.8 & 0.06 & 87.7 & 0.04 & 5.4 & 0.46 & 2176 & 2 \\
\hline
\end{tabular}

a A minimum of two independent measures was made on each case. The standard deviation is also given. 
Raquel B. Gómez-Coca, Rosario Cruz-Hidalgo, Gabriel D. Fernandes, Daniel Barrera-Arellano, María del Carmen Pérez-Camino, and Wenceslao Moreda / American Journal of Agricultural Science and Technology

(2015) Vol. 3 No. 1 pp. 24-37

\subsection{Statistical Analysis}

Figure 2 shows the main correlations obtained after Spearman correlation analysis, using IBM SPSS Statistics software. Focusing on (E)SG, a statistical study was conducted in order to relate their presence with some quality and purity parameters such as acidity value, FAAE concentration, etc. The program gives possible relationships between some of the parameters under study but with no causality association. Therefore there is a call to caution since we cannot interpret that the increase / decrease of a parameter causes an increase / decrease of another, but that when a parameter is increased / decreased also the other one presents similar behavior. Among all considered possibilities, only SG and ESG seem to show a tendency to relate with each other (Figure 2a). Actually, although the coefficient of determination (R2) is too low $(<0.5)$ the relation coefficient is above 0.75 . This, together with the fact of having a relatively large number of samples suggests the observed trend as acceptable. Similar reasoning applies to the relationship with the acidity values (Figure 2b). It is clear that a correlation coefficient $>0.75$ can still be low; however, since it was not possible to establish any correlation among the studied parameters this information can be very important for future work. Finally, PCA did not provide a clear distribution pattern to establish any relationship between the (E)SG presence and other virgin olive oil minor compounds.

Table 4 Fatty Acid Alkyl Esters (FAAE) Content (mg.kg-1), Acidity Value (\% Free Oleic Acid), Wax $\left(\mathrm{mg} \cdot \mathrm{kg}^{-1}\right)$ and Aliphatic Alcohol Concentrations $\left(\mathrm{mg} \cdot \mathrm{kg}^{-1}\right)$ of Olive Oil from Different Cultivars. ${ }^{\text {a }}$

\begin{tabular}{|l|ll|ll|ll|ll|}
\hline & \multicolumn{2}{|c|}{ FAAE } & \multicolumn{2}{c|}{ Acidity } & \multicolumn{2}{c|}{ Waxes } & \multicolumn{2}{c|}{ Alcohols } \\
Samples & mg.kg-1 & SD & \% & SD & mg.kg-1 & SD & mgkg-1 & SD \\
\hline Adramitini & 11.85 & 2.48 & 0.80 & 0.01 & 90 & 2 & 131 & 28 \\
Ascolana & 6.02 & 0.59 & 0.30 & 0.01 & 78 & 4 & 47 & 1 \\
Blanqueta & 5.68 & 0.18 & 0.29 & 0.01 & 59 & 3 & 26 & 1 \\
Bouteillan & 6.53 & 0.46 & 0.37 & 0.01 & 94 & 1 & 26 & 1 \\
Chemlal K. & 11.53 & 0.66 & 0.19 & 0.01 & 18 & 1 & 7 & 1 \\
Cipresino & 4.90 & 0.44 & 0.26 & 0.01 & 95 & 1 & 54 & 1 \\
Coratina & 5.18 & 0.11 & 0.39 & 0.01 & 31 & 1 & 7 & 1 \\
Empeltre & 4.73 & 0.43 & 0.23 & 0.01 & 81 & 8 & 48 & 3 \\
Frantoio & 5.22 & 0.08 & 0.27 & 0.01 & 73 & 3 & 76 & 15 \\
Hojiblanco & 4.32 & 0.20 & 0.17 & 0.01 & 30 & 2 & 45 & 11 \\
Imperial & 3.60 & 0.25 & 0.19 & 0.01 & 54 & 3 & 22 & 1 \\
Kalamon & 3.15 & 0.71 & 0.19 & 0.01 & 41 & 2 & 16 & 1 \\
Koroneiki & 5.70 & 0.02 & 0.18 & 0.01 & 60 & 2 & 39 & 23 \\
Leccino & 4.98 & 0.31 & 0.17 & 0.01 & 68 & 2 & 69 & 6 \\
Lechín & 14.26 & 1.77 & 0.36 & 0.01 & 49 & 3 & 70 & 3 \\
Manzanilla & 7.68 & 0.27 & 0.81 & 0.01 & 60 & 2 & 68 & 1 \\
Negral & 5.56 & 0.03 & 0.23 & 0.01 & 47 & 3 & 22 & 1 \\
Nevado A. & NQ & & 0.26 & 0.01 & NQ & & 51 & 12 \\
Pendolino & 3.42 & 0.31 & 0.21 & 0.01 & 96 & 4 & 170 & 24 \\
Picual & 1.45 & 0.05 & 0.17 & 0.01 & 39 & 1 & 14 & 1 \\
Rapasayo & NQ & & 0.11 & 0.01 & 29 & 1 & 13 & 1 \\
Sigoise & 4.13 & 0.14 & 0.30 & 0.01 & 48 & 1 & 28 & 1 \\
\hline
\end{tabular}

a A minimum of two independent measures was made on each case. The standard deviation is also given. 
Raquel B. Gómez-Coca, Rosario Cruz-Hidalgo, Gabriel D. Fernandes, Daniel Barrera-Arellano, María del Carmen Pérez-Camino, and Wenceslao Moreda / American Journal of Agricultural Science and Technology

(2015) Vol. 3 No. 1 pp. 24-37
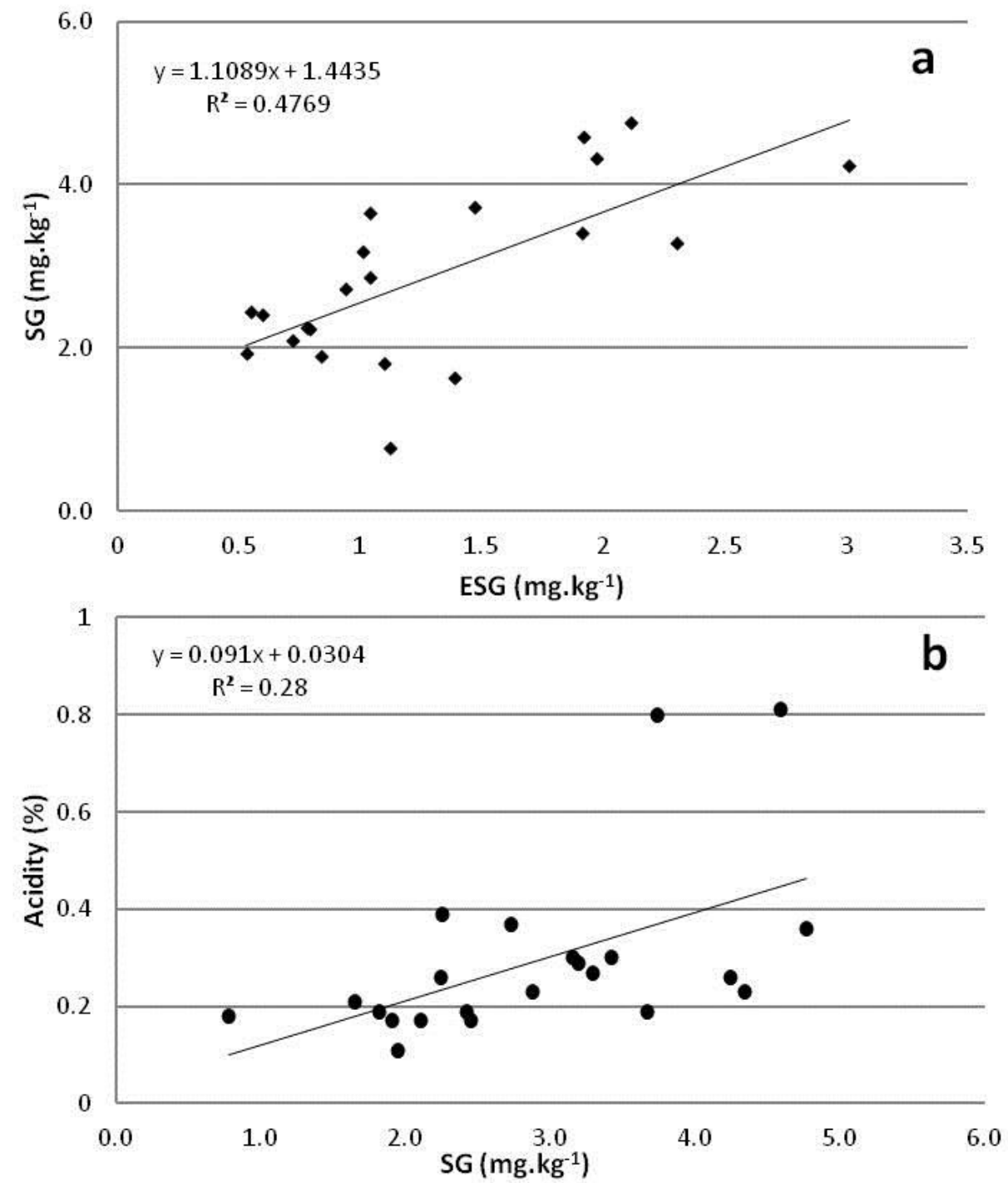

Fig. 2. Relationship between a) total free and esterified steryl glucosides (SG and ESG, respectively) and $b$ ) between SG and acidity values.

\section{Conclusions}

This work has provided an overall view of the situation regarding (E)SG. Undoubtedly a higher number of independent measures, in which individual variables are under strict control, are needed in order to draw definite conclusions on the determining factors of the (E)SG presence in virgin olive oil. Even if (E)SG formation depends on the presence of FS, up to date there is not a known, direct and stoichiometric relationship between the main substrates: FS, FFA, SG, and ESG. Besides, (E)SG are not cultivar specific as far as the content is concerned, which allows us to establish 
Raquel B. Gómez-Coca, Rosario Cruz-Hidalgo, Gabriel D. Fernandes, Daniel Barrera-Arellano, María del Carmen Pérez-Camino, and Wenceslao Moreda / American Journal of Agricultural Science and Technology

(2015) Vol. 3 No. 1 pp. 24-37

quantitative limits for the (E)SG presence in virgin olive oil. Interestingly, regarding composition (see the case of ESSG) they might be species distinctive. These conclusions lead unavoidably to the following questions: are some of the studied species cultivar specific? If so, could this fact be utilized as a tool for possible single-variety oil identification? Is there a relationship between the amount of water utilized during oil extraction and the presence of (E)SG? Is it somehow reflected on the SG:ESG ratio? How and when does the ESG formation occur? Do all possible fatty acids behave in the same way? Finally, given how 'fashionable' all kinds of nutritional supplements have become one should wonder if consumers are being properly informed of the regular presence of beneficial compounds such as those studied here in natural matrices such as virgin olive oil.

\section{Conflict of Interest}

The authors declare no competing financial or another kind of interest.

\section{References}

Bondioli, P. (2009). Nature of some insoluble materials recovered from biodiesel samples. European Journal of Lipid Science and Technology, 111, 814-821.

http://dx.doi.org/10.1002/ejlt.200800211

Buckland, G., \& González, C. A. (2010). Trends in olive oil production, supply and consumption in Mediterranean countries from 1961 to the present day.In Olives and olive oil in health and disease prevention (pp. 689-698). Academic Press, London, MA, CA http://dx.doi.org/10.1016/B978-0-12-374420-3.00072-3

Christopoulou, E., Lazaraki, M., Komaitis, M., \& Kaselimis, K. (2004). Effectiveness of determinations of fatty acids and triglycerides for the detection of adulteration of olive oils with vegetable oils. Food Chemistry, 84, 463-474. http://dx.doi.org/10.1016/S0308-8146(03)00273-5

Damirchi, S. A, Savage, P. G, \& Dutta, C. P. (2005). Sterol Fractions in Hazelnut and Virgin Olive Oils and 4,4Dimethylsterols as Possible Markers for Detection of Adulteration of Virgin Olive Oil. Journal of the American Oil Chemist Society, 82, 717-725. http://dx.doi.org/10.1007/s11746-005-1133-y

European Commission Regulation (1991). EEC 2568/91 of 11 July on the characteristics of olive oil and olive-residue oil and on the relevant methods of analysis. Official Journal of the European Community, 248, 1-102.

European Commission Regulation (2013a). EEC 1348/2013 of 16 December amending Regulation (EEC) No $2568 / 91$ on the characteristics of olive oil and olive-residue oil and on the relevant methods of analysis. Official Journal of the European Community, 338, 31-67.

European Commission Regulation (2013b). EEC 299/2013 of 26 March amending Regulation (EEC) No 2568/91 on the characteristics of olive oil and olive-residue oil and on the relevant methods of analysis. Official Journal of the European Community, 228, 52-70.

Gómez-Coca, R. B., Cruz-Hidalgo, R., Fernandes, G., Pérez-Camino, M. C., \& Moreda, W. (2014b) Analysis of methanol and ethanol in virgin olive oil. MethodsX, 1, 207-211.

http://dx.doi.org/10.1016/j.mex.2014.09.002

Gómez-Coca, R. B., Fernandes, G., Aguila-Sánchez, C., Pérez-Camino, M. C, \& Moreda, W. (2014a). Comparative Study of Phytosterol Derivatives in Monovarietal Olive Oils. Journal of Agricultural and Food Chemistry, 
Raquel B. Gómez-Coca, Rosario Cruz-Hidalgo, Gabriel D. Fernandes, Daniel Barrera-Arellano, María del Carmen Pérez-Camino, and Wenceslao Moreda / American Journal of Agricultural Science and Technology

(2015) Vol. 3 No. 1 pp. 24-37

62, 5669-5674.

http://dx.doi.org/10.1021/jf501340q

Gómez-Coca, R. B., Pérez-Camino, M.C., \& Moreda, W. (2012). Specific procedure for analysing steryl glucosides in olive oil. European Journal of Lipid Science and Technology, 114, 1417-1426. http://dx.doi.org/10.1002/ejlt.201200181

Gómez-Coca, R. B., Pérez-Camino, M.C., \& Moreda, W. (2013). On the glucoside analysis: simultaneous determination of free and esterified steryl glucosides in olive oil. Detailed analysis of standards as compulsory first step. Food Chemistry, 15, 1273-1280.

http://dx.doi.org/10.1016/i.foodchem.2013.03.080

Grille, S., Zaslawski, A., Swantje, T., Plat, J., \& Warnecke, D. (2010). The functions of steryl glucosides come to those who wait: Recent advances in plants, fungi, bacteria and animals. Progress in Lipid Research, 49, 262-288.

http://dx.doi.org/10.1016/j.plipres.2010.02.001

International Olive Council (2003). Determination of the content of aliphatic alcohols by capillary gas chromatography. COI/T.20/Doc. No 26, 1-11.

International Olive Council (2011). Guide for the determination of the characteristics of oil olives. COI/OH/Doc. No 1, 1-41.

International Olive Council (2012). Determination of the content of waxes, fatty acid methyl esters and fatty acid ethyl esters by capillary gas chromatography using 3 grams of silica. COI/T.20/Doc. No 31, 1-17.

International Olive Council (2013a). Trade standard applying to olive oils and olive-pomace oils. COI/T.15/NC No 3/Rev. 7, 1-19.

International Olive Council (2013b). Determination of the composition and content of sterols and triterpene dialcohols by capillary column gas chromatography. COI/T.20/ Doc. No 30/Rev. 1, 1-19.

Lacoste, F., Dejean, F., Griffon, H., \& Rouquette, C. (2009). Quantification of free and esterified steryl glucosides in vegetable oils and biodiesel. European Journal of Lipid Science and Technology, 111, 822828. http://dx.doi.org/10.1002/ejlt.200800297

Lin, X., Ma, L., Moreau, R. A., \& Ostlund, R. E. Jr. (2011). Glycosidic bond cleavage is not required for phytosteryl glycoside-induced reduction of cholesterol absorption in mice. Lipids, 46, 701-708. http://dx.doi.org/10.1007/s11745-011-3560-2

Lin, X., Ma, L., Racette, S. B., Anderson, C. L., \& Ostlund, R. E. Jr. (2009). Phytosterol glycosides reduce cholesterol absorption in humans. American Journal of Physiology-Gastrointestinal and Liver Physiology, 296, G931-G935. http://dx.doi.org/10.1152/ajpgi.00001.2009

Mackay, D. S., \& Jones, P. J. H. (2011). Phytosterols in human nutrition: type, formulation, delivery, and physiological function. European Journal of Lipid Science and Technology, 113, 1427-1432. http://dx.doi.org/10.1002/ejlt.201100100

Münger, H. L., \& Nyström, L. (2014). Enzymatic hydrolysis of steryl glycosides for their analysis in foods. Food Chemistry, 163, 202-211. http://dx.doi.org/10.1016/i.foodchem.2014.04.082

Nyström, L., Schär, A., \& Lampi, A.-M.. (2012). Steryl glycosides and acylated steryl glycosides in plant foods reflect unique sterol patterns. European Journal of Lipid Science and Technology, 114, 656-669. http://dx.doi.org/10.1002/ejlt.201200033

Pollak, O. J. (1953). Reduction of blood cholesterol in man. Circulation, 7, 702-706. http://dx.doi.org/10.1161/01.CIR.7.5.702

Vossen, P. (2013). Growing olives for oil. In Handbook of olive oil. Analysis and properties (pp. 19-56). 
Raquel B. Gómez-Coca, Rosario Cruz-Hidalgo, Gabriel D. Fernandes, Daniel Barrera-Arellano, María del Carmen Pérez-Camino, and Wenceslao Moreda / American Journal of Agricultural Science and Technology (2015) Vol. 3 No. 1 pp. 24-37

Springer New York-Heidelberg-Dordrecht-London. http://dx.doi.org/10.1007/978-1-4614-7777-8_2 